\title{
Evaluation of the blunt thoracic trauma caused by solid sports ball impacts
}

\author{
Narasimha THOTA****, Jayantha EPAARACHCHI** and Kin Tak LAU** \\ *CAD-CAE Consultants \\ 45 Horley Tce, Adelaide, South Australia 5084, Australia \\ E-mail: tnmurthy@cae-consultants.com.au \\ ${ }^{* *}$ Centre of Excellence in Engineered Fibre Composites \\ University of Southern Queensland, Toowoomba, Queensland 4350, Australia
}

Received 29 May 2014

\begin{abstract}
Evaluation of the thoracic injury due to blunt impacts during the contact and collision sports activity is very crucial for the development and validation of the chest protectors for the athletes and safety balls of the sports such as cricket, baseball, lacrosse and the golf. In order to evaluate the thoracic injury due to solid sports ball impacts, a series of nonlinear transient dynamic, finite element simulations were carried out by impacting the FE model surrogate of the thorax "MTHOTA" (Mechanical THOrax for Trauma Assessment) with a baseball (both soft-core and synthetic) and a cricket ball at impact speed of $10-45 \mathrm{~m} / \mathrm{s}$, with an increment of $5 \mathrm{~m} / \mathrm{s}$. Only for the impact speed for which measured $\mathrm{VC}_{\max }$ was $1 \mathrm{~m} / \mathrm{s}$, further simulations were carried out by introducing the ball spin $(1000-8000 \mathrm{rpm}$, with an increment of $1000 \mathrm{rpm})$. Soft-core baseball, synthetic baseball and cricket ball impacts have caused $\mathrm{VC}_{\max }=1.0 \mathrm{~m} / \mathrm{s}$ ( $25 \%$ probability for AIS3+ injuries) at impact speeds of 30.7 $\mathrm{m} / \mathrm{s}, 27.9 \mathrm{~m} / \mathrm{s}$ and $23.2 \mathrm{~m} / \mathrm{s}$ respectively. For the normal impacts, spin (about impact direction and two directions perpendicular to the impact direction) of the ball has got no impact on the blunt thoracic trauma. At usual pitching speeds, soft-core baseball didn't offer any safety and performance point of view, it was found to be as bad as synthetic baseball. Deflection response of the MTHOTA and the solid sports ball - MTHOTA energy interactions have yielded $\mathrm{VC}_{\max } \propto\left[\left(\mathrm{TE}_{\max }\right)^{1.748} \text {, (Time rate of } \mathrm{KE}_{\max }\right)^{0.9489}$, (Deformation velocity max $^{2.3227}$, and $\left(\right.$ Impact velocity baseball $^{2.548}$ ]. Similarly, Stored Energy Criterion and Energy Storing Rate Criterion (Wang, 1989) have yielded the relations Peak stored energy $\propto(\text { Peak deflection мтнотА })^{1.253}$ and Rate of peak stored energy $\propto(\text { Peak deflection MTHOTA } \times \text { Rate of peak deflection мтнотА })^{0.5554}$.
\end{abstract}

Keywords: Thorax surrogate, MTHOTA, Baseball, Cricket ball, Force response, Deflection response, Viscous criterion, Stored Energy Criterion, Energy Storing Rate Criterion.

\section{Introduction}

Injuries are very common during the sports activities such as cricket, baseball, hockey, rugby, and footy (Bell, 1992; Davids \& Morgan, 1988; Elliott, et al., 1995; Walker, et al., 2010) . Injuries could be due to collision between the players, collision with the barricades along the boundary, due to the solid sports ball impacts and due to movements used by the athletes for the sports activity. Solid sports ball impacts can cause injuries ranging from minor sprains and bruises to chest wall injury including rib fractures. The latter, depending upon the location and number, may be further complicated by secondary phenomenon like flail chest, pulmonary contusion, hemothorax, pneumothorax, rupture of the aorta, among others. Although a variety of recreational and competitive sporting activities may lead to thoracic wall injuries and its sequelae, this paper evaluates thoracic injuries caused only by solid sports ball impact. 
Blunt chest impact, depending upon the location and time of the impact, can also cause commotio-cordis, which is a fatal cardiac arrhythmia caused by functional re-entry and ventricular fibrillation (Doerer, et al., 2007; Madias, et al., 2007; Maron \& Estes III, 2010). Due to its peculiarly specific nature, commotio-cordis has to be dealt separately from the viscous injury related aspects. Therefore, only structural damage related thoracic injuries caused by the solid sports ball impacts were evaluated and presented in the paper. Viscous criterion (the product of the chest deformation velocity and chest compression), which is the best predictor of the structural damage of the thorax has been used throughout the paper.

Very limited research has been carried out in the area of evaluation of the thoracic injuries due to solid sports ball impacts. Janda et al., (1992) have impacted the thoraces of the child crash test dummy and $5^{\text {th }}$ percentile female Hybrid III with the baseballs (both soft core and standard) and evaluated the viscous responses. They have extended the experiments to assess the effectiveness of the chest protectors (generic closed cell foam and various other materials) available in the market. Closed cell foam sheet protectors of any thickness, definitely to a certain extent, would attenuate impact force. Surprisingly, results obtained from the experiments, they have concluded that chest protectors are not only ineffective in reducing the viscous response of the thorax also increased the risk of chest injury and fatal cardiac arrhythmia as they exacerbated the impact force. Thoraces of the crash test dummies used for automotive simulated crash tests are very stiff and are not suitable for obtaining the force and displacement responses due to impacts by blunt ballistics. Therefore, the study conducted by Janda et al., (1992) is not useful for the comparison with the results presented in the study.

Janda et al., (1998) have experimentally investigated relative risk of fatal cardiac injury by impacting 3-RCS surrogate of the thorax designed for the evaluation of viscous injury due to blunt ballistic impacts with various soft-core baseballs at 17.9, 22.4 and $26.8 \mathrm{~m} / \mathrm{s}$ impact speeds. From the results obtained, they have concluded that as far as the commotio-cordis concerned, soft-core balls offer no benefit when compared with the standard baseballs. Though 3-RCS has got some limitations (for example, very less effective impact area which is only 2 inch by 3 inch at the centre of the middle rib, smaller in size, not validated for cardiac loads etc.), the experiments are relevant to the study. But impacts considered for the study are well below the normal speeds encountered by baseball players. (Viano, et al., 2000) have evaluated the effectiveness of the chest protectors by impacting the 3-RCS surrogate with and without chest protectors by a standard baseball at 17.9, 22.4, 26.8 and $31.2 \mathrm{~m} / \mathrm{s}$. By comparing the viscous injury in both cases, they have concluded that chest protectors offer no significant benefit. Due to above mentioned limitations of the 3-RCS and also there is no provision to attach the chest protector to the 3-RCS to simulate the real life situation, only viscous injury results obtained for the unprotected 3-RCS can be used for the comparative purposes. However, usual pitching speeds of the baseball even in the youth sports ( 9 - 18 years) goes beyond $95 \mathrm{mph}$ (i.e., $>42.5 \mathrm{~m} / \mathrm{s}$ ). Therefore, authors have made an attempt to evaluate the structural damage due to solid sports ball impacts (with the realistic pitching speeds, a wider range of impact speeds $(10-45 \mathrm{~m} / \mathrm{s}$, with an increment of the $5 \mathrm{~m} / \mathrm{s}))$ in terms of known engineering parameters (viscous criterion: $\mathrm{VC}_{\max }$ ). For this purpose, authors have used a thorax surrogate MTHOTA (Thota, et al., 2014), which is validated with the human response corridors developed by WSU's researchers (Bir, 2000). Human response corridors, being developed for the projectile impacts to the thoraces of the human cadavers for the impact conditions very much relevant to the solid sports ball impacts to the thorax, the usage of MTHOTA as the thorax surrogate for the present study is justified.

Baseball kinematics, MTHOTA's biomechanical responses, MTHOTA-baseball interactions, $\mathrm{VC}_{\max }$ values and their relation to energy interactions of MTHOTA-baseball, due to direct impact (with and without ball spin) were presented in this paper.

\section{Methodology}

\subsection{Details of the impact tests}

In order to evaluate the blunt thoracic injury caused by the solid baseball impacts, a series of impact analyses were carried out, in virtual testing environment, by impacting a FE model surrogate MTHOTA with the following solid sports balls.

a) A soft-core baseball of $75 \mathrm{~mm}$ diameter and 146 grams weight.

b) A synthetic baseball of $75 \mathrm{~mm}$ diameter and 146 grams weight and 
c) A cricket ball of $75 \mathrm{~mm}$ diameter and 160 grams weight.

Realistic pitching speeds were considered as impact speeds and for every sports ball, 8 impacts speeds $(10-45 \mathrm{~m} / \mathrm{s}$ with an increment of $5 \mathrm{~m} / \mathrm{s}$ ) were considered. So far, no researchers have examined the spin of the impacting ball. Therefore, Spin of the ball with respect to impact direction (y-axis) and perpendicular to the impact direction (both $\mathrm{x}$ and $\mathrm{z}$-axes). Spin, $1000-8000 \mathrm{rpm}$ with an increment of $1000 \mathrm{rpm}$, was considered in the simulations. To evaluate the effect of the spin of the ball on the structural damage of the thorax, only for one velocity case with 8 ball cases of ball spin in each direction $(\mathrm{x}, \mathrm{y}$ and $\mathrm{z}-$ axes) were carried out and results were presented in this paper.

\subsection{Details of the thorax surrogate}

By measuring force-time, deflection-time and force-deflection responses of thoraces of 9 human cadavers when subjected to 3 impact conditions (140 gram wooden baton at $20 \mathrm{~m} / \mathrm{s}$ and $40 \mathrm{~m} / \mathrm{s}$ impact speeds, 30 gram wooden baton at $60 \mathrm{~m} / \mathrm{s}$ ), Wayne state university researchers established human response corridors. A finite element model of the thorax surrogate made up of corrugations of the Aluminium was developed and correlated with these human response corridors (Bir, et al., 2004; Bir \& Viano, 2004; Bir, 2000; Thota, et al., 2014; Thota, et al., 2012). Cross section of the FE model of the thorax surrogate is shown in the "Fig. 1".

Impact conditions used for the development of the human response corridors and impacts of the solid sports balls fall under the category of blunt ballistic impacts (i.e., projectile of mass $20-200$ gram with impact speeds of $20-250$ $\mathrm{m} / \mathrm{s}$ ). Therefore, MTHOTA can be effectively used for the evaluation of the blunt thoracic trauma caused by the solid sport ball impacts. MTHOTA facilitates the calculation of the trauma in terms of $\mathrm{VC}_{\max }$.

Though there were two methods to evaluate the $\mathrm{VC}_{\max }$ using the $\mathrm{FE}$ model surrogate, only first method has been employed in this paper. More details about development and validation of MTHOTA surrogate can be found in the published literature (Thota, et al., 2014).

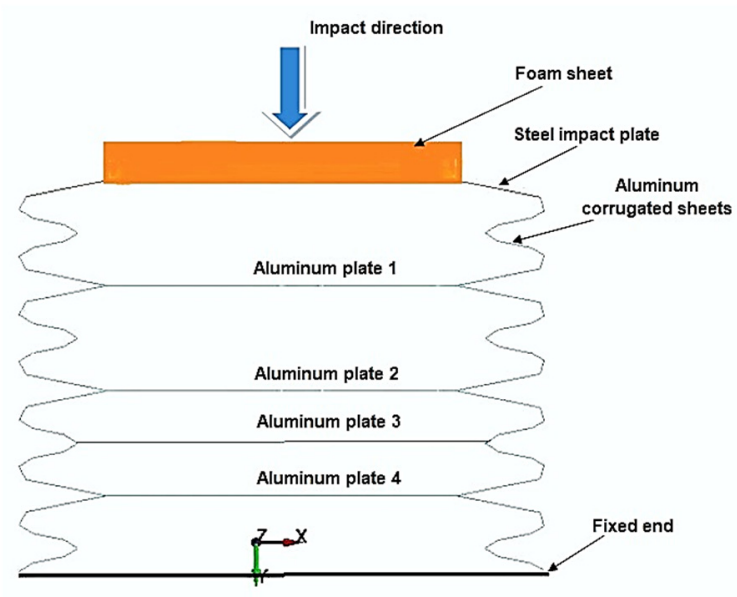

Fig.1 Cross section of the MTHOTA FE model surrogate

MTHOTA surrogate is correlated such a way that, equation given below directly provides the value of $\mathrm{VC}_{\max }$

$$
\begin{aligned}
& \mathrm{VC}_{\max }=\quad \mathrm{S} .\left(\mathrm{Y}_{\max } / \mathrm{D}\right) .\left(\mathrm{Y}_{\max } / \mathrm{T}\right) \\
& \mathrm{Where} \\
& \mathrm{VC}_{\max }=\text { Viscous Criterion } \\
& \mathrm{S}=\text { Scaling factor }=0.366 \text { for MTHOTA surrogate } \\
& \mathrm{Y}_{\max }=\text { Max deflection of the impact plate } \\
& \mathrm{D}=\text { Dummy constant }=110 \mathrm{~mm} \text { for MTHOTA surrogate } \\
& \mathrm{T}=\text { Duration at which } \mathrm{Y}=\mathrm{Y}_{\max }
\end{aligned}
$$

For frontal loading on the thorax (Viano \& King, 2000; Viano, et al., 1989), 


$$
\begin{aligned}
\mathrm{VC}_{\max } & =1.0 \mathrm{~m} / \mathrm{s} ; & & 25 \% \text { probability of AIS3+ } \\
& =1.3 \mathrm{~m} / \mathrm{s} ; & & 50 \% \text { probability of AIS3+ }
\end{aligned}
$$

\subsection{Finite element model of the solid sports ball}

Though many leagues introduced strict regulations on the baseball bats, there are several types of baseballs as they are selected purely based on the size, weight and COR at $26.8 \mathrm{~m} / \mathrm{s}$ (Drane \& Sherwood, 2004). A typical league baseball is made up of a small cork centre within the two rubber layers as the core, covered with thick wool winding layer and stitched synthetic leather cover. Many researchers carried out finite element simulations of baseball for the performance evaluation, using LS-DYNA software. For the FE model of the baseball, homogeneous linear elastic sphere (Crisco, et al., 2002; Crisco, et al., 1997), linear viscoelastic model (Nicholls, et al., 2006; Smith, 2001), hyperelastic model (Mustone \& Sherwood, 1998), viscoelastic and hyperelastic models (Munroe \& Sherwood, 2012) were used. From the published work (Smith, 2001), the performance related parameters of the baseball obtained from the numerical simulations were very well correlated with those from the experiments. Therefore, a linear viscoelastic model, which is a simplest approximation to represent the time-dependent, non-Hookean deformation, was considered for the baseball modeling.

Material data and material model (MAT_006, MAT_VISCOELASTIC of LS-DYNA non-linear finite element software) were given in Table 1.

\begin{tabular}{|c|c|c|c|c|}
\hline S.No. & Parameter & Description & Soft-core baseball & Synthetic baseball \\
\hline 1 & Material model & $\begin{array}{r}\text { Linear } \\
\text { Viscoelastic }\end{array}$ & \multicolumn{2}{|c|}{ MAT_006 (LS-DYNA) } \\
\hline 2 & $\begin{array}{l}\text { Shear relaxation } \\
\text { behavior of the } \\
\text { baseball material is } \\
\text { described by: }\end{array}$ & $\mathrm{G}(\mathrm{t})=\mathrm{G}_{\infty}+\left(\mathrm{G}_{0}-\mathrm{G}_{\infty}\right) \mathrm{e}^{-\beta \mathrm{t}}$ & \multicolumn{2}{|c|}{ From the published research (Hallquist, 2007; } \\
\hline$\underline{3}$ & $\mathrm{RO}$ & Mass density & \multicolumn{2}{|c|}{$6.325 \times 10^{-7} \mathrm{~kg} / \mathrm{mm}^{3}$} \\
\hline 4 & BULK & $\begin{array}{l}\text { Elastic bulk } \\
\text { modulus }\end{array}$ & $0.069 \mathrm{GPa}$ & $0.019 \mathrm{GPa}$ \\
\hline 5 & $\mathrm{G}_{0}$ & $\begin{array}{l}\text { Short-time } \\
\text { shear modulus }\end{array}$ & $0.041 \mathrm{GPa}$ & $0.002 \mathrm{GPa}$ \\
\hline 6 & $\mathrm{G}_{\infty}$ & $\begin{array}{r}\text { Long-time } \\
\text { shear modulus }\end{array}$ & $0.011 \mathrm{GPa}$ & $0.001 \mathrm{GPa}$ \\
\hline 7 & $\beta$ & Decay constant & $9000 \mathrm{~Hz}$ or $9000 \mathrm{~s}^{-1}$ & $1250 \mathrm{~Hz}$ or $1250 \mathrm{~s}^{-1}$ \\
\hline 8 & \multicolumn{2}{|c|}{ Weight of the baseball } & \multicolumn{2}{|c|}{140 gram (both soft-core and synthetic) } \\
\hline
\end{tabular}

Table 1 Material data and model for baseballs (soft core and synthetic) used in the present study

Some convergence studies related to the baseball and other solid sports balls were available in the literature. As the impact cases are not relevant, authors have performed convergence studies to finalize the FE model of the baseball used in the present study. The baseball FE model details are given in Table 2, and the ball FE models (cross section and full) were shown in the "Fig. 2".

Table 2 Details of the FE model of the solid sports ball

\begin{tabular}{|l|l|}
\hline FE entity & comments \\
\hline Nodes & 17589 \\
\hline Elements & Hex8 brick elements $-16360 ;$ Penta6 (wedge elements) $-200 ;$ \\
\hline Element size & Smallest $3 \mathrm{~mm}$, longest side $5 \mathrm{~mm}$ \\
\hline Element formulations & ELFORM $=1$ and AET $=2$ were used \\
\hline Ball-MTHOTA interface & CONTACT_SURFACE_TO_SURFACE \\
\hline
\end{tabular}



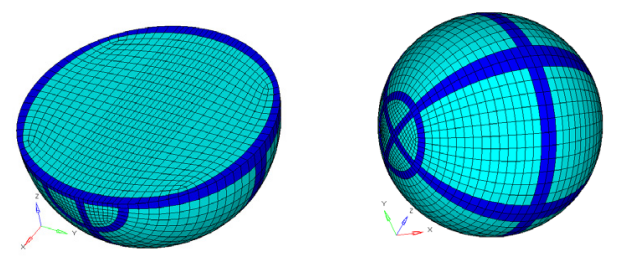

Fig. 2 Finite Element model of the solid sports ball

As the ball used in the cricket game is almost of the same size as a baseball, FE model shown in the "Fig 2" was used for all simulations related to cricket ball impacts. MOONEY_RIVLIN_RUBBER material model (MAT_027 of LSDYNA software) was used for a cricket ball, and material properties were taken from the published literature (Cheng, et al., 2011). Material data used for a cricket ball FE model and details of the MOONEY_RIVLIN_RUBER material model are given in Table 3 .

Table 3 MOONEY_RIVLIN_RUBBER material data and model details used for a cricket ball FE model

\begin{tabular}{|c|c|c|}
\hline Material parameter & Details & Comments \\
\hline & $\mathrm{W}=\mathrm{A}(\mathrm{I}-3)+\mathrm{B}(\mathrm{II}-3)+\mathrm{C}\left(\mathrm{III}^{-2}-1\right)+\mathrm{D}(\mathrm{III}-1)^{2}$ & \multirow{5}{*}{$\begin{array}{c}\text { From the published } \\
\text { literature } \\
\text { (Cheng, et al., } \\
\text { 2011; Hallquist, }\end{array}$} \\
\hline Strain energy & I, II and III are invariants of right Cauchy-Green Tensor & \\
\hline density function & $\mathrm{C}=0.5 \mathrm{~A}+\mathrm{B}$ & \\
\hline & $\mathrm{D}=[\mathrm{A}(5 \mu-2)+\mathrm{B}(11 \mu-5)] /(2-4 \mu)$ & \\
\hline Shear modulus & & \\
\hline of linear elasticity & $2(\mathrm{~A}+\mathrm{B})$ & \multirow{5}{*}{ 2007; Tanaka, et al., } \\
\hline $\begin{array}{l}\mu \text { (Poisson's } \\
\text { ratio) }\end{array}$ & Value between 0.49 and 0.5 recommended & \\
\hline$\rho$ (mass density) & $7.8 \times 10^{-7} \mathrm{~kg} / \mathrm{mm}^{3}$ & \\
\hline A & 0.00402 & \\
\hline B & $-4.1 \times 10^{-4}$ & \\
\hline Weight of the ball & 165 gram & \\
\hline
\end{tabular}

\section{Results and discussion}

\subsection{Viscous injury due to solid sports ball impacts and its calculation}

To evaluate dynamic force response function of impact time, dynamic deflection response function of impact time, thoracic injury owing to the baseball impact in terms of $\mathrm{VC}_{\max }$, MTHOTA's foam sheet was impacted with the soft-core baseball with speeds of $10-45 \mathrm{~m} / \mathrm{s}$, with an increment of $5 \mathrm{~m} / \mathrm{s}$.. By post-processing the simulation results, deflectiontime response of the MTHOTA for all impact cases were elicited and shown in the "Fig. 3". Various stages of the MTHOTA during baseball impact (for $30 \mathrm{~m} / \mathrm{s}$ impact speed) were shown in the "Fig. 4".

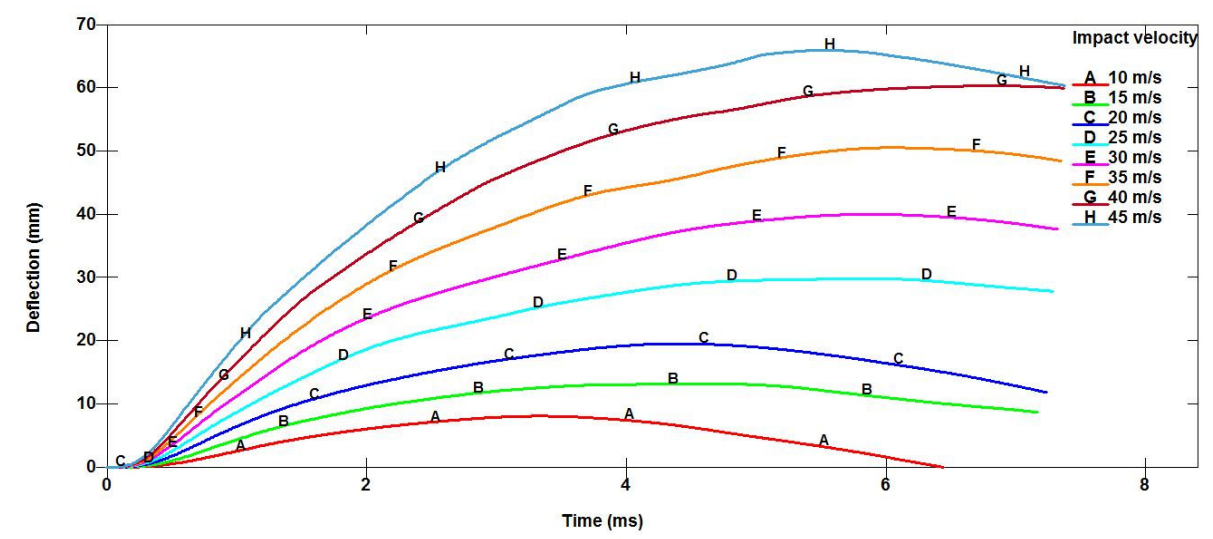

Fig. 3 Deflection - time response of the MTHOTA when subjected to impacts of soft core baseball 


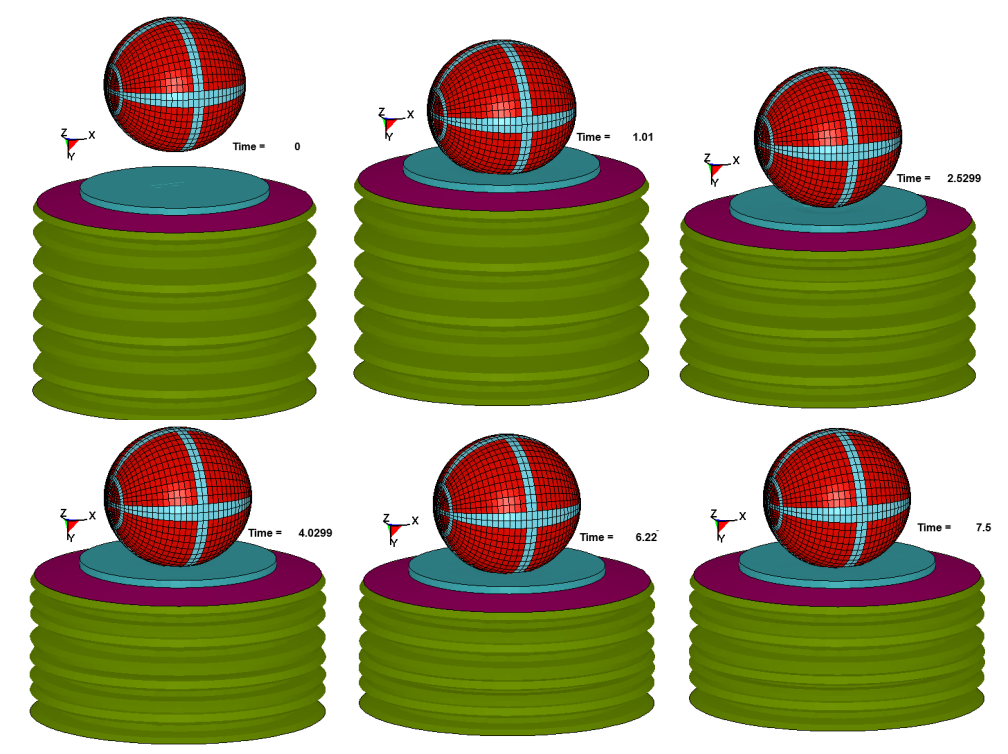

Fig. 4 Various stages of the MTHOTA when subjected to the soft core baseball impact at $30 \mathrm{~m} / \mathrm{s}$

Similarly, deflection-time responses of the MTHOTA surrogate were obtained by impacting it with the synthetic baseball and cricket ball with 8 impact speeds considered for the present study. $\mathrm{VC}_{\max }$ values were calculated for all impact cases ( 3 sports balls and 8 impact speeds for each ball) by substituting the maximum deflection of the impact plate and the time at which deflection is highest, in the Eq. (1) and were shown the "Fig. 5".

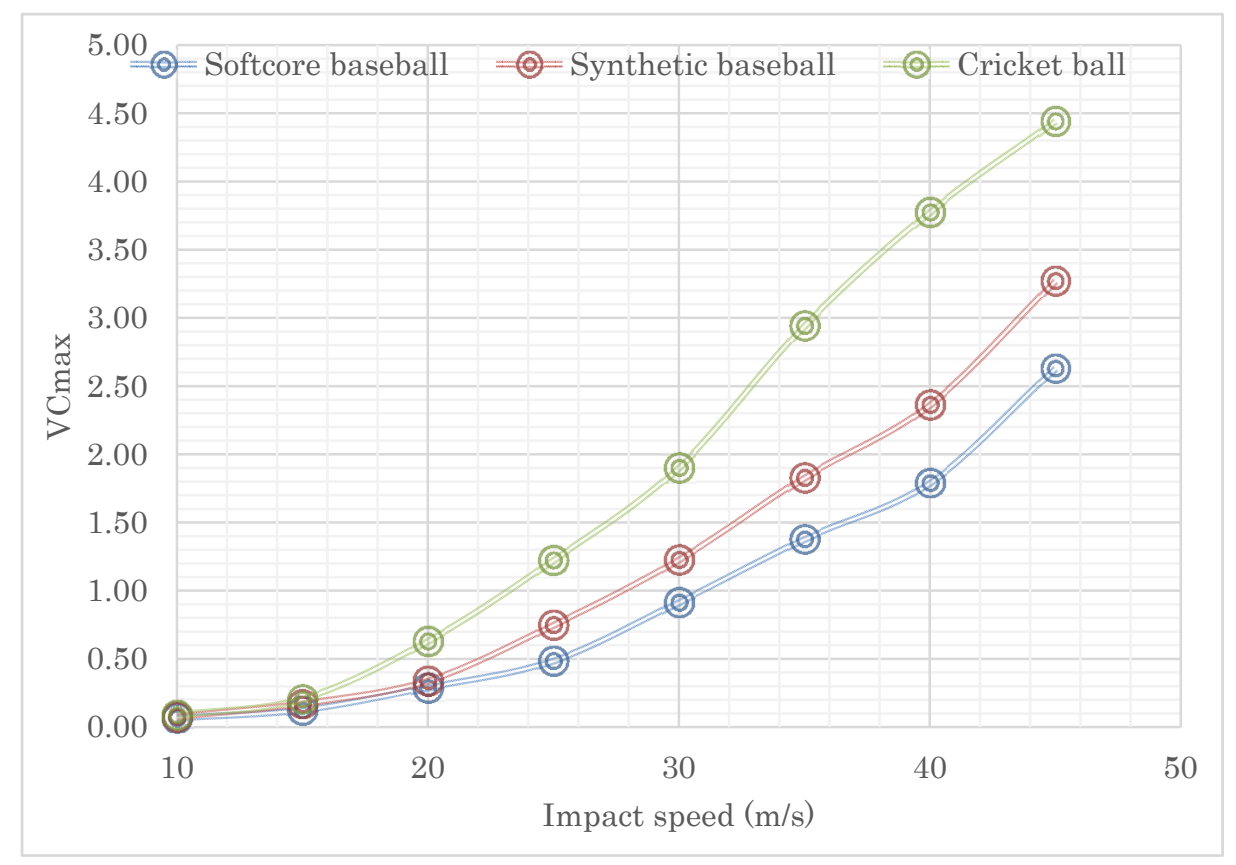

Fig. 5 Influence of the material, weight and impact speed on the VCmax

Soft-core baseball, synthetic baseball and cricket ball impacting at $30.7 \mathrm{~m} / \mathrm{s}, 27.9 \mathrm{~m} / \mathrm{s}$ and $23.2 \mathrm{~m} / \mathrm{s} \mathrm{respectively,} \mathrm{have}$ caused injuries equivalent to $\mathrm{VC}_{\max }=1 \mathrm{~m} / \mathrm{s}$ (i.e., $25 \%$ percent probability for AIS3+ injuries). This clearly shows that material and weight of the solid sports balls have got significant effect on the thoracic injuries. Though soft-core baseball has better injury performance when compared to the other two balls considered, the injuries caused are fatal at usual pitching speeds. 
Only soft-core baseball impacts were envisaged for the study of kinematics, energy interactions and influence of the rate of change in maximum kinetic energy, rate of change in maximum total energy and ball spin on the $\mathrm{VC}_{\max }$.

\subsection{Kinematics of the impacting ball}

Ball kinematics is imperative in evaluation of the impact force. Product of the mass of the ball and deceleration of the centre node of the ball during any instance gives the impact force at that particular duration. Force - time response of MTHOTA subjected to soft-core baseball impacts were shown in the "Fig. 6".

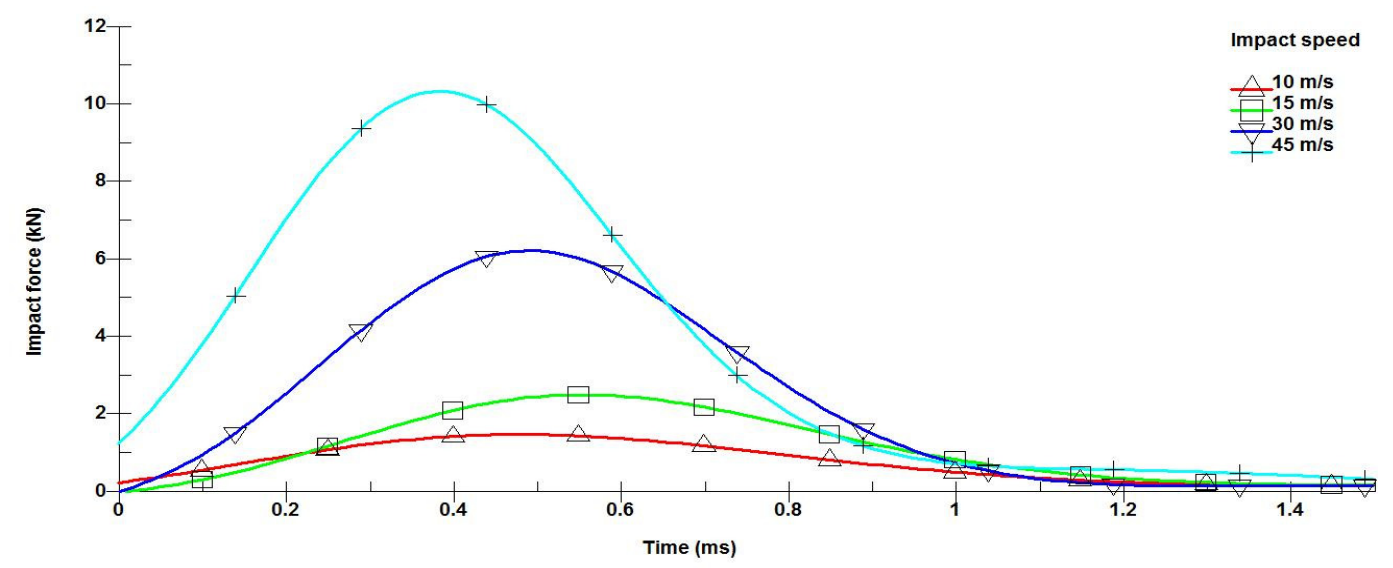

Fig. 6 Dynamic force response of MTHOTA when subjected to the soft core baseball impacts

Average impact force may be used for the evaluation of the percentage risk of commotio-cordis (Dau, 2012). In the present study, commotio-cordis is not considered and also viscous criterion is the accurate predictor of the blunt thoracic trauma, force-time response has got no importance in the present study

\subsection{Energy interactions of the solid sports ball and the MTHOTA surrogate}

For the study of energy interactions (during the impact) between the MTHOTA with the solid sports ball, only softcore baseball was considered. These interactions for the impact speed of $30 \mathrm{~m} / \mathrm{s}$ were shown in the "Fig. 7 ".

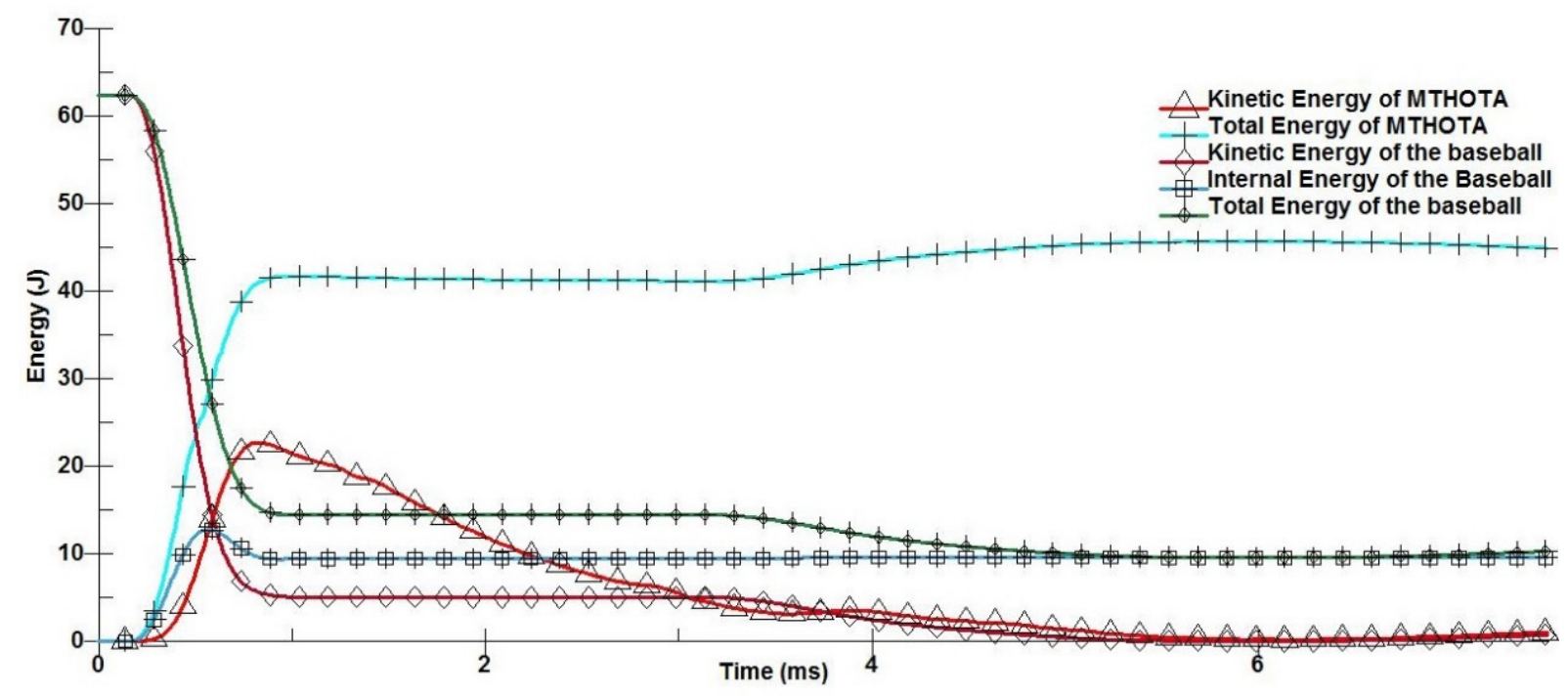

Fig. 7 Energy interactions of soft core baseball and MTHOTA surrogate (impact speed $30 \mathrm{~m} / \mathrm{s}$ ) 
During the impact of MTHOTA with the baseball, let us say,

\begin{tabular}{|c|c|}
\hline $\mathrm{KE}_{\text {ini.baseball }}$ & $=$ Initial kinetic energy of the baseball \\
\hline $\mathrm{KE}_{\text {t.baseball }}$ & $=$ Kinetic energy of a baseball at given instance " $\mathrm{t}$ " \\
\hline $\mathrm{IE}_{\text {t.baseball }}$ & $=$ Internal energy of a baseball at given instance " $\mathrm{t}$ " \\
\hline $\mathrm{TE}_{\mathrm{t} . \text { baseball }}$ & $=$ Total energy of a baseball at given instance " $\mathrm{t}$ " \\
\hline $\mathrm{KE}_{\text {t.MTHOTA }}$ & $=$ Kinetic energy of the surrogate at given instance " $t$ " \\
\hline IE & $=$ Internal energy of the surrogate at given instance " $t$ " \\
\hline TE $_{\text {t.MTHOTA }}$ & $=$ Total energy of the surrogate at given instance " $\mathrm{t}$ " \\
\hline
\end{tabular}

From the law of conservation of energy,

$$
\begin{aligned}
& \mathrm{KE}_{\text {ini.baseball }}-\mathrm{TE}_{\mathrm{t} . \text { basebal }}=\mathrm{TE}_{\mathrm{t} . \mathrm{MTHOTA}} \\
& \mathrm{TE}_{\mathrm{t} \text {.MTHOTA }}=\mathrm{KE}_{\mathrm{t} . \text { MTHOTA }}+\mathrm{IE}_{\mathrm{t} . \text { MTHOTA }}
\end{aligned}
$$

Using Eq. (2), Eq. (3) and "Fig.7", energy transactions between MTHOTA and the baseball (blunt projectile) can be evaluated for any instance of the impact duration. From the analytical studies performed on Lobdell lumped mass model of the thorax, it was clear that $\mathrm{VC}_{\max }$ is significantly influenced by rate of the maximum kinetic energy of the thorax and rate of the deformation of the thorax (Wang, 1989). Therefore, from the output, Maximum of total Energy (TE $E_{\max }$ ), maximum of kinetic energy of MTHOTA $\left(\mathrm{KE}_{\max }\right)$ were evaluated from the output. $\mathrm{VC}_{\max }$ values (from the Eq. (1) and the "Fig. 4") were plotted against the rate of change in $\mathrm{TE}_{\max }$ and rate of change in $\mathrm{KE}_{\max }$. The plots were shown in the "Fig. 8" and "Fig. 9" respectively.

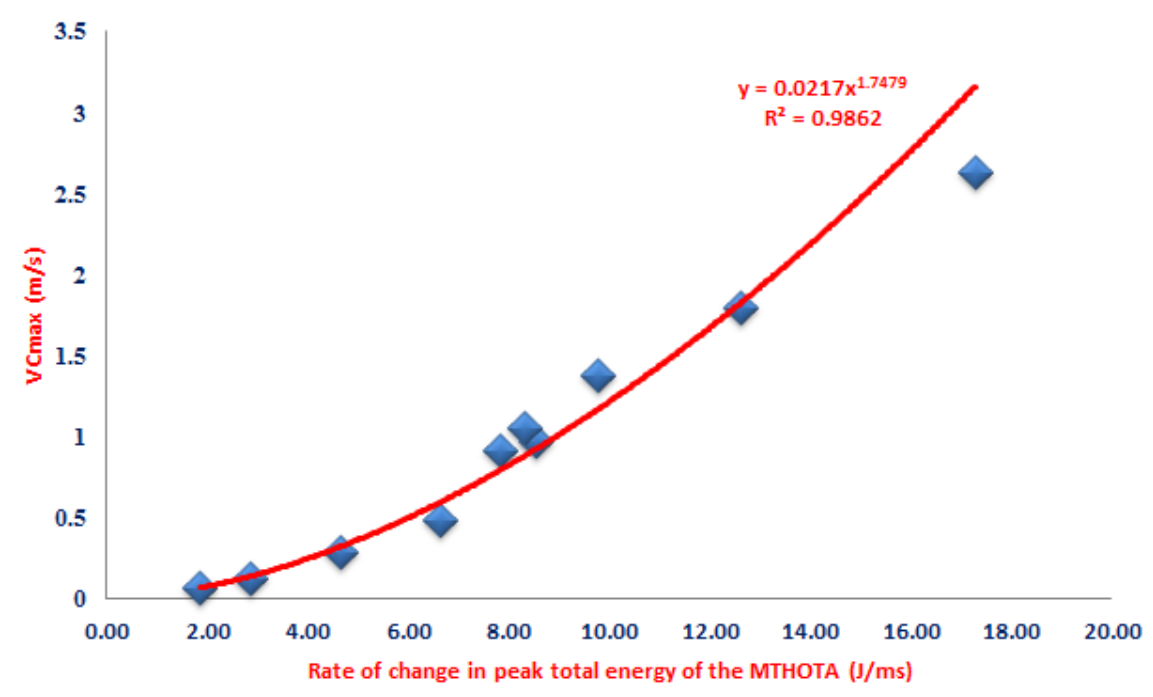

Fig. 8 Influence of the rate of maximum total energy of MTHOTA on $\mathrm{VC}_{\max }$

Power law curve fitted well for the VCmax vs. Rate of maximum total energy of the MTHOTA, and the trend line is given below.

$$
\begin{array}{ll}
\mathrm{VC}_{\max } & =0.0217\left(\mathrm{TE}_{\max }\right)^{1.7479} \\
\mathrm{TE}_{\max } & =\text { Maximum total energy of the MTHOTA (in J) } \\
\mathrm{t} & =\text { Impact duration at which total energy is maximum (in ms) }
\end{array}
$$




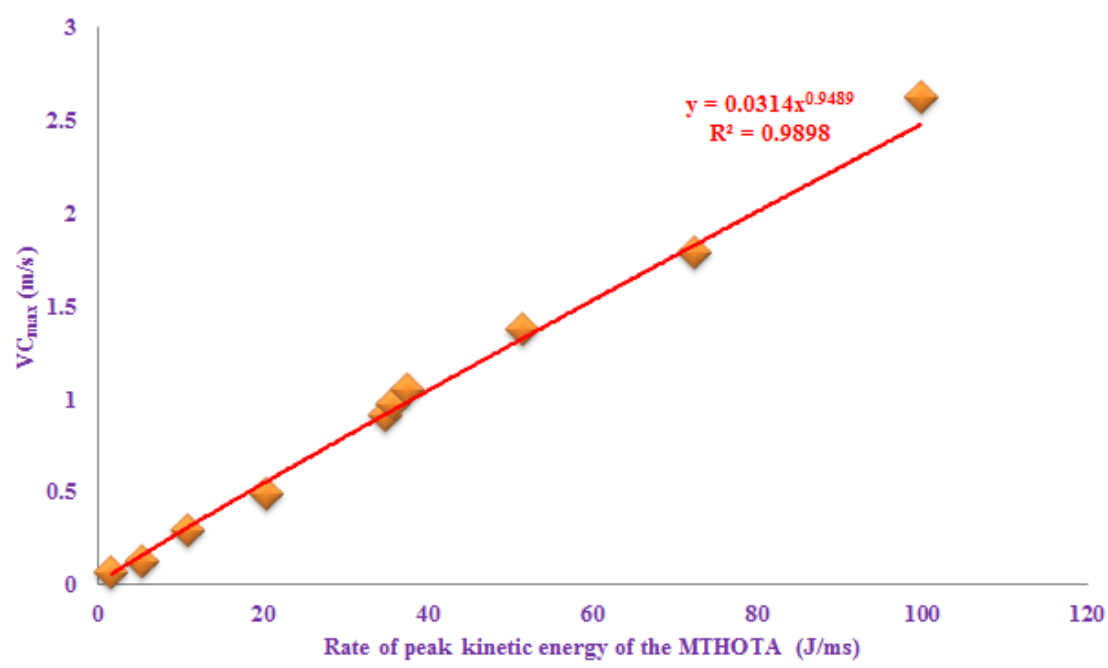

Fig. 9 Influence of the rate of maximum kinetic energy of the MTHOTA surrogate on the VCmax

The relation obtained by power-law curve fitting is given below.

$$
\mathrm{VC}_{\max } \quad=0.0314\left(\mathrm{KE}_{\max } / \mathrm{t}\right)^{0.9489}
$$

Where,

$$
\begin{aligned}
& \mathrm{VC}_{\max } \quad \text { = viscous criterion (in } \mathrm{m} / \mathrm{s} \text { ) } \\
& \mathrm{KE}_{\max } \quad \text { = Maximum kinetic energy of the MTHOTA surrogate (in J) } \\
& \mathrm{t} \quad=\text { impact duration at which kinetic energy is maximum (in ms) }
\end{aligned}
$$

The Eq. (5), due to the good match between the trend line and the plot showing the variation of the $\mathrm{VC}_{\max }$ with the rate of change in $\mathrm{KE}_{\max }$, it can be used for evaluating $\mathrm{VC}_{\max }$ for other impact cases.

\subsection{Influence of the deformation velocity of the MTHOTA on the injury}

$\mathrm{VC}_{\max }$ values calculated were plotted against the maximum deformation velocity obtained from the output of the impact simulations ("Fig. 10").

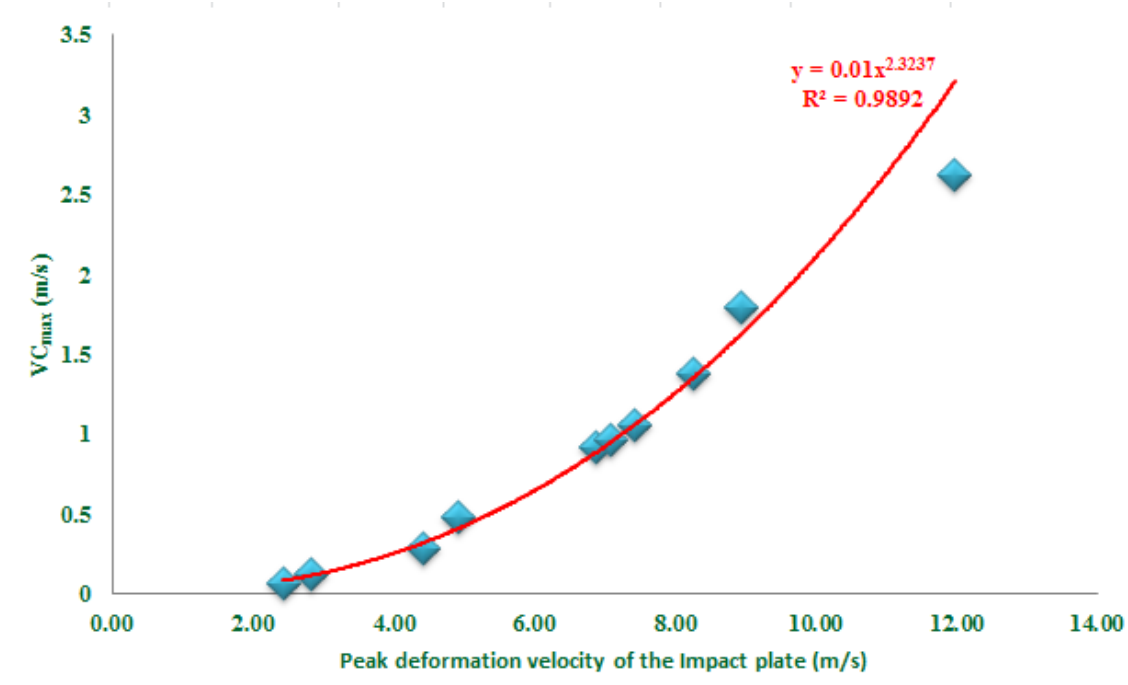

Fig. 10 Influence of the deformation velocity of MTHOTA

From the plot of $\mathrm{VC}_{\max }$ versus maximum deformation velocity of MTHOTA, power-law curve fitting yielded the following relation. 


$$
\mathrm{VC}_{\max } \quad=0.01\left(\mathrm{Y}_{\max } / \mathrm{t}\right)^{2.3237}
$$

Where,

$\mathrm{Y}_{\max }=$ Maximum deformation of the impact plate of the MTHOTA, in mm

$\mathrm{t} \quad=$ Impact duration at which the deformation is maximum, in $\mathrm{ms}$

\subsection{Effect of the impact velocity on the thoracic injury}

$\mathrm{VC}_{\max }$ values obtained for the soft-core baseball impacts were plotted against the impact speed and shown in the "Fig. 11".

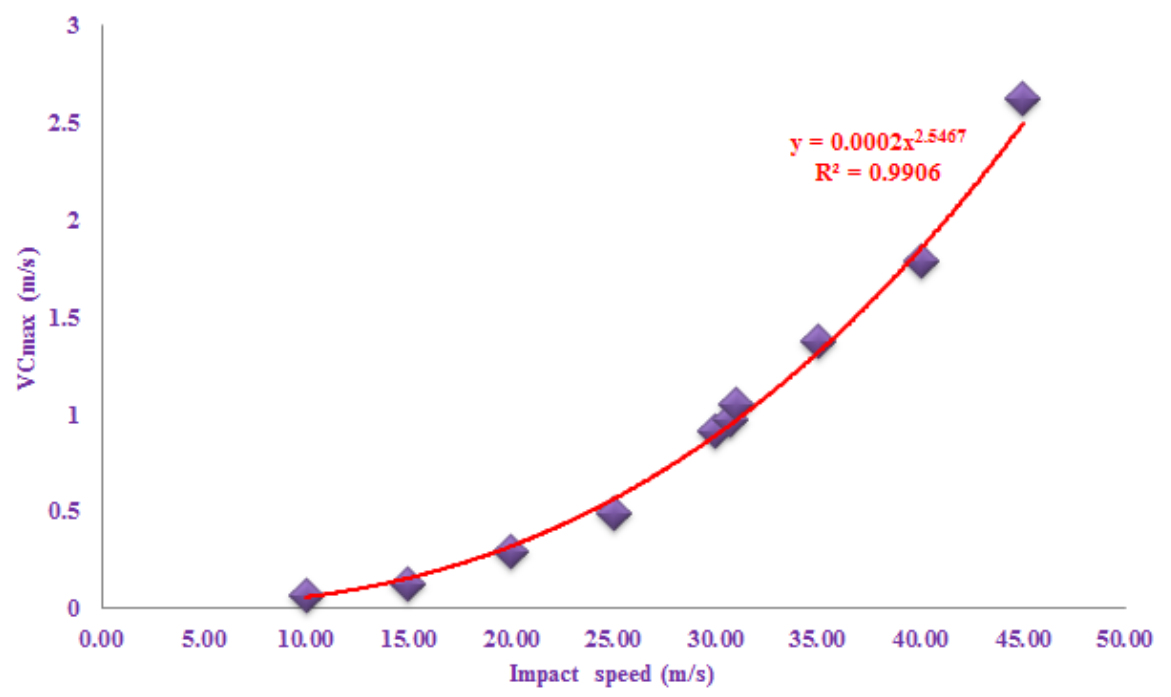

Fig. 11 Influence of the impact speed of soft core baseball on the viscous injury

The relation between baseball impact speed and the thoracic injury $\left(\mathrm{VC}_{\max }\right)$ is given below.

$$
\begin{aligned}
& \mathrm{VC}_{\max } \quad=0.0002(\mathrm{v})^{2.548} \\
& \text { Where, } \\
& \mathrm{v}=\text { baseball impact speed in } \mathrm{m} / \mathrm{s}
\end{aligned}
$$

As the injury is greatly influenced by the projectile diameter and material, the Eq. (7) can used only for the baseball used in the analysis, for extrapolation or interpolation of the $\mathrm{VC}_{\max }$ for various impact speeds.

\subsection{Stored Energy Criterion and Energy Storing Rate Criterion}

Though the viscous criterion is widely used and accepted as the best predictor of the blunt thoracic trauma in terms of known engineering parameters, the physical meaning of the criterion was unclear. Wang (1989) has carried out study using the mathematical model of the thorax (Lobdell, et al., 1973) to analyse the fundamental properties of the viscous criterion and evaluated 4 criteria. Of these, 'Stored Energy Criterion' relates the peak energy stored in the thorax and peak deflection of the thorax, while 'Energy Storing Rate Criterion' relates the peak energy storing rate, peak thorax deflection and time rate of thorax deflection. Analytical expressions derived by Wang (1989) were given below.

Stored Energy Criterion, according to which maximum stored energy is proportional to the square of the maximum deflection of the thorax.

$$
\mathrm{IE}_{\max } \propto\left(\mathrm{y}_{\max }\right)^{2}
$$

Where,

$\mathrm{IE}_{\max }=$ Peak stored energy or Peak internal energy of the thorax 


$$
\mathrm{Y}_{\max }=\text { Peak thorax deflection }
$$

Energy Stored Rate Criterion, according to which rate of maximum stored energy is proportional to the product of the peak deflection of the thorax and its time rate.

$$
\left(\mathrm{IE}_{\max } / \mathrm{T}\right) \propto\left(\mathrm{y}_{\max }\right)\left(\mathrm{dy} \mathrm{max}_{\max } / \mathrm{dt}\right)
$$

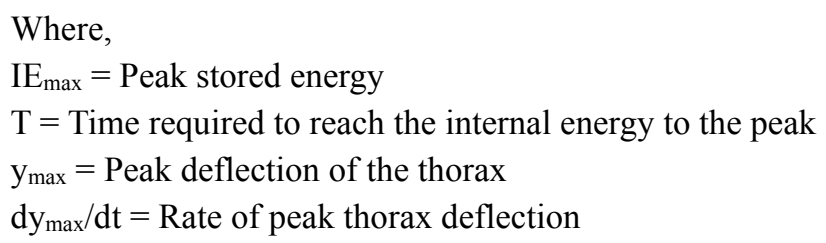

From the outcome of the virtual experiments carried out by impacting the MTHOTA with the soft-core baseball, stored energy criterion and energy storing rate criterion were evaluated and the plots pertaining to these criteria were as shown in the "Fig. 12" and "Fig. 13" respectively.

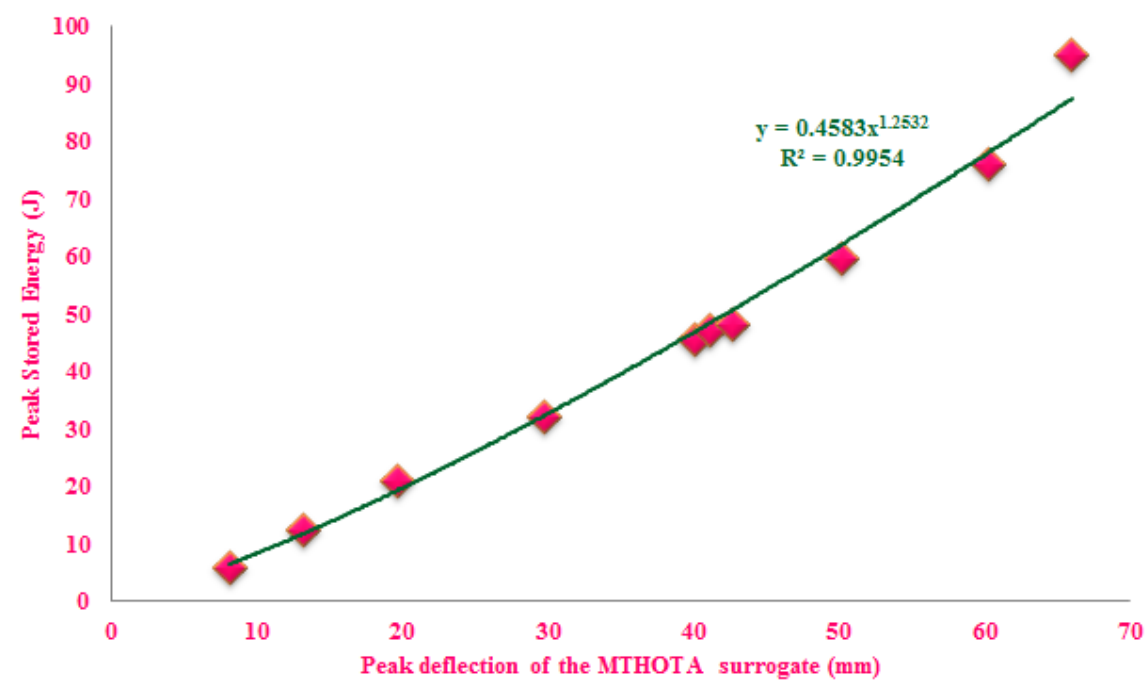

Fig 12 Stored energy criterion derived from the MTHOTA - baseball interactions

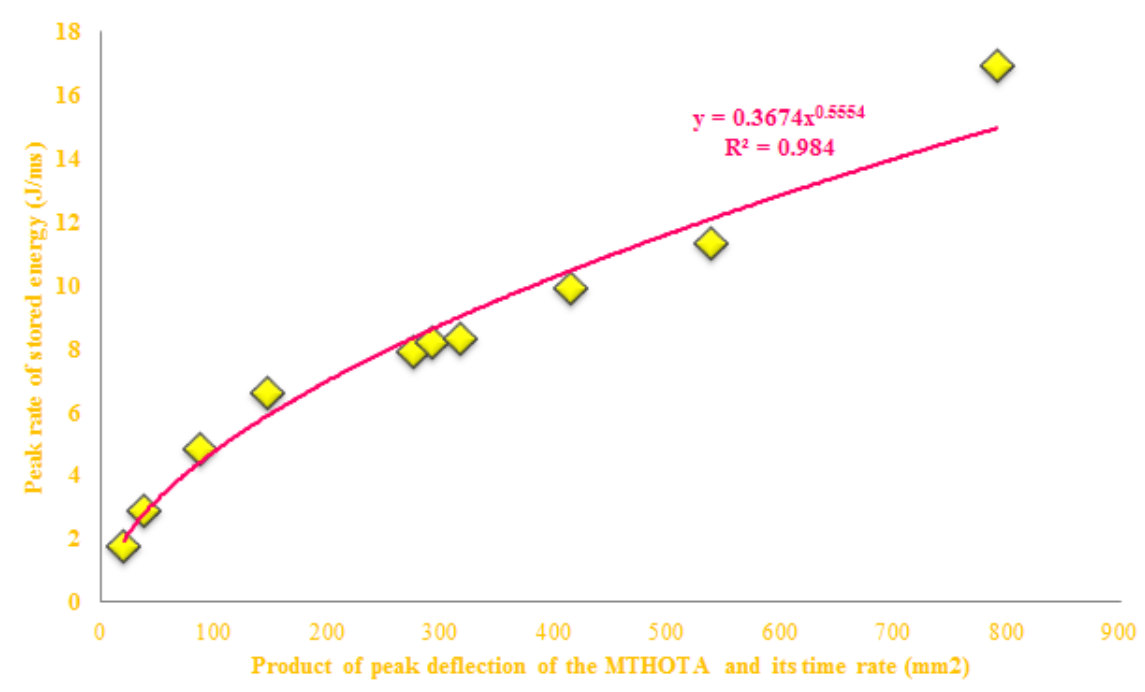

Fig 13 Energy storing rate criterion derived from the MTHOTA - baseball interactions 
From the outcome of the simulations in which MTHOTA subjected to baseball impacts, peak internal energy of the MTHOTA and its time rate, peak deflection of the MTHOTA and its time rate have yielded energy storing criterion and energy storing rate criterion as:

$$
\mathrm{IE}_{\max } \propto\left(\mathrm{y}_{\max }\right)^{1.2532}
$$

and

$$
\left(\mathrm{IE}_{\max } / \mathrm{T}\right) \propto\left(\mathrm{y}_{\max } \times \mathrm{dy} \mathrm{max}_{\max } / \mathrm{dt}\right)^{0.5554}
$$

respectively.

It is important to note that Lobdell's lumped mass mathematical model of the thorax is suitable for automotive applications and not applicable for ballistic impact applications (Bir, 2000). Because of the same reason, Eq. (10) and Eq. (11) were not correlated with those obtained from the analytical studies of Wang (1989).

\subsection{Effect of the ball spin on the thoracic injury}

Effect of ball spin on the thoracic injury is unknown as no one has conducted experiments or analytical study. In the case of baseball, during the game, depending upon the ball bat interaction, baseball spins ranging from $1000-8000 \mathrm{rpm}$. Therefore, to elucidate the effect of the baseball spin on the blunt trauma, a series of simulations were carried out for the following impact conditions.

$$
\begin{array}{ll}
\text { Baseball impact speed } & =30.5 \mathrm{~mm} / \mathrm{ms} \text { and } \\
\text { Baseball spin about X, Y and Z axes } & =1000-8000 \mathrm{rpm} \text {, with an increment of } 1000 \mathrm{rpm} .
\end{array}
$$

In all, 24 simulation runs were carried out to evaluate the effect of the baseball spin on the injury. From each output, rate of change in $\mathrm{KE}_{\max }$ and $\mathrm{TE}_{\max }$ were assessed (Table 4). Maximum deflection of the impact plate could not be calculated due to the eccentric collapse of the corrugated structure. Various stages of the MTHOTA during the impact with a baseball $(30.7 \mathrm{~m} / \mathrm{s}$ impact speed and $8000 \mathrm{rpm}$ anti-clockwise spin about Z-axis) are shown in the "Fig. 14"

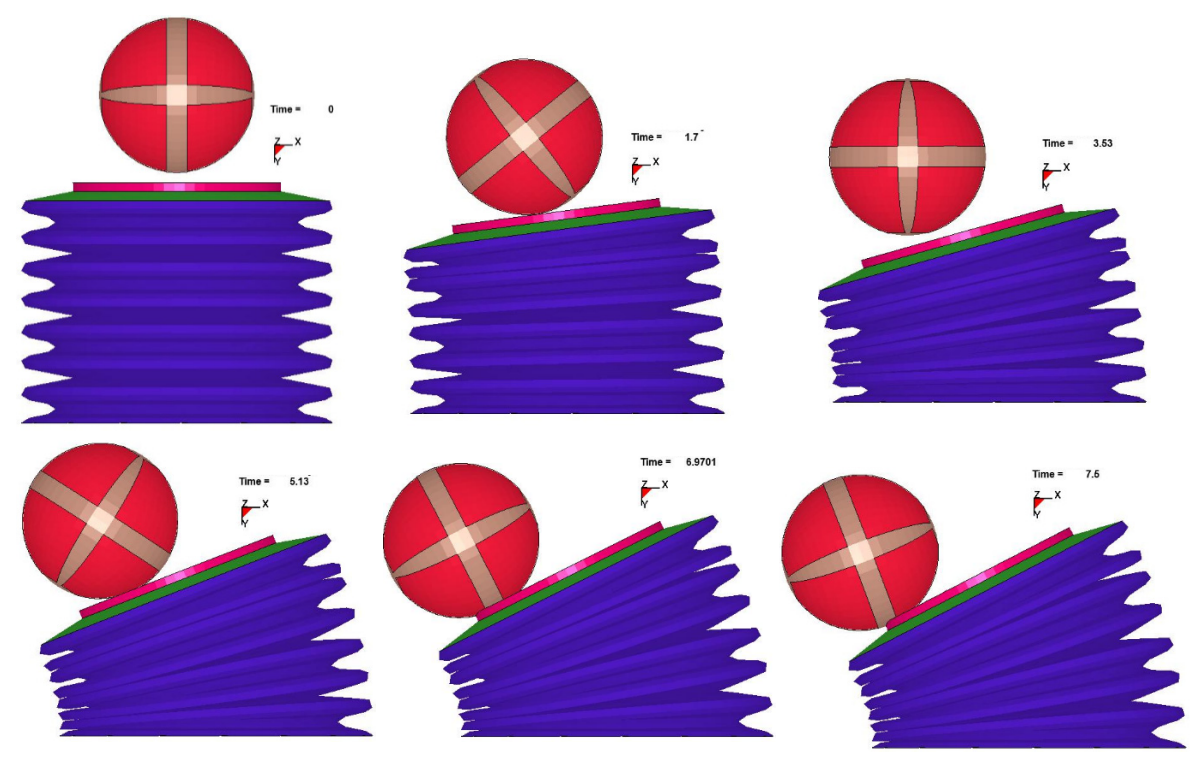

Fig. 14 Stages of the MTHOTA surrogate when impacted with a soft-core baseball with $30.7 \mathrm{~m} / \mathrm{s}$ impact speed and $8000 \mathrm{rpm}$ spin 
Table 4 Rate of change in kinetic energy and the total energy of the surrogate

\begin{tabular}{|c|c|c|c|c|c|c|c|c|}
\hline \multicolumn{2}{|c|}{ Anticlockwise spin } & \multirow[t]{2}{*}{$\begin{array}{l}\text { Kinetic } \\
\text { energy }\end{array}$} & \multicolumn{6}{|c|}{ MTHOTA surrogate } \\
\hline \multicolumn{2}{|r|}{ Baseball } & & \multicolumn{2}{|c|}{ Spin about $\mathrm{X}$-axis } & \multicolumn{2}{|c|}{ Spin about Y-axis } & \multicolumn{2}{|c|}{ Spin about $\mathrm{Z}$-axis } \\
\hline $\begin{array}{l}\text { Impact } \\
\text { speed in } \\
\mathrm{mm} / \mathrm{ms}\end{array}$ & $\begin{array}{l}\text { Spin in } \\
\text { rpm }\end{array}$ & $\begin{array}{c}\text { Total } \\
\text { initial } \\
\text { energy }(\mathbf{J})\end{array}$ & $\begin{array}{c}\text { Rate of } \\
\text { KEmax } \\
(\mathbf{J} / \mathbf{m s})\end{array}$ & $\begin{array}{c}\text { Rate of } \\
T_{\text {max }} \\
(\mathbf{J} / \mathbf{m s})\end{array}$ & $\begin{array}{c}\text { Rate of } \\
\text { KEmax } \\
(\mathrm{J} / \mathrm{ms})\end{array}$ & $\begin{array}{c}\text { Rate of } \\
T E_{\max } \\
(\mathbf{J} / \mathbf{m s})\end{array}$ & $\begin{array}{c}\text { Rate of } \\
\text { KEmax } \\
(\mathrm{J} / \mathrm{ms})\end{array}$ & $\begin{array}{c}\text { Rate of } \\
\text { TE }_{\max } \\
(\mathrm{J} / \mathrm{ms})\end{array}$ \\
\hline 30.7 & 1000 & 64.94 & 35.80 & 7.80 & 35.80 & 8.20 & 36.38 & 7.62 \\
\hline 30.7 & 2000 & 66.24 & 36.11 & 7.73 & 35.80 & 8.15 & 36.41 & 8.70 \\
\hline 30.7 & 3000 & 68.37 & 36.15 & 7.78 & 35.55 & 8.14 & 36.88 & 7.77 \\
\hline 30.7 & 4000 & 71.36 & 36.94 & 7.74 & 35.21 & 8.10 & 37.03 & 7.73 \\
\hline 30.7 & 5000 & 75.21 & 37.33 & 7.64 & 35.49 & 8.12 & 37.46 & 7.67 \\
\hline 30.7 & 6000 & 80.00 & 37.99 & 7.66 & 35.53 & 8.10 & 37.61 & 7.59 \\
\hline 30.7 & 7000 & 85.55 & 38.40 & 8.07 & 35.37 & 8.08 & 37.78 & 7.92 \\
\hline 30.7 & 8000 & 92.08 & 38.81 & 9.11 & 35.34 & 7.98 & 38.50 & 8.36 \\
\hline
\end{tabular}

Due to the eccentric collapse of the MTHOTA for the baseball spin about $\mathrm{X}$ and $\mathrm{Z}$ axes, it is not possible for evaluating the unique maximum deflection of the impact plate. For the case of baseball spin about Y-axis, the collapse was normal without any imbalance. Eq. (6) and Eq. (7) can be used to evaluate the $\mathrm{VC}_{\max }$ based on the MTHOTA's rate of maximum TE and rate of maximum KE. The Eq. (5) was considered for the evaluation of the $\mathrm{VC}_{\max }$ for all 24 cases of baseball spins, using the rate of maximum KE of MTHOTA obtained from the simulation outcome and tabulated (Table 5). For comparison purposes, $\mathrm{VC}_{\max }$ values calculated by using the rate of maximum deflection of the impact plate (for only the baseball spinning about Y-axis) were given in the same Table 5.

Table 5 Effect of the ball spin on the $\mathrm{VC}_{\max }$

\begin{tabular}{|c|c|c|c|c|c|c|c|}
\hline & \multirow{2}{*}{$\begin{array}{c}\text { Anti- } \\
\text { clockwise }\end{array}$} & \multicolumn{2}{|c|}{$\begin{array}{r}V_{\text {max }}= \\
0.0314\left(K_{\text {max }} / t\right)^{0.9489}\end{array}$} & \multirow[t]{2}{*}{ Eq. (5) } & \multicolumn{3}{|c|}{$\begin{array}{c}\text { For } Y \text {-spin, } \\
V_{C_{\max }}=\mathrm{S} . \\
\left(\mathrm{Y}_{\max } / \mathrm{D}\right) \cdot\left(\mathrm{d} \mathrm{Y}_{\max } / \mathrm{dt}\right) \\
\mathrm{Eq} \cdot(\mathbf{1})\end{array}$} \\
\hline $\begin{array}{c}\text { Baseball } \\
\text { impact } \\
\text { speed } \\
\text { in } \\
\mathrm{mm} / \mathrm{ms}\end{array}$ & & X-spin & Y-Spin & & $\begin{array}{c}\text { Maximum } \\
\text { deflection }\end{array}$ & $\begin{array}{c}\text { Time at } \\
\text { Maximum } \\
\text { deflection }\end{array}$ & $V C_{\max }$ \\
\hline 30.7 & 1000 & 0.94 & 0.94 & 0.95 & 41.06 & 5.85 & 0.96 \\
\hline 30.7 & 2000 & 0.95 & 0.94 & 0.96 & 41.20 & 5.90 & 0.96 \\
\hline 30.7 & 3000 & 0.95 & 0.93 & 0.97 & 41.21 & 5.90 & 0.96 \\
\hline 30.7 & 4000 & 0.97 & 0.93 & 0.97 & 41.20 & 5.90 & 0.96 \\
\hline 30.7 & 5000 & 0.98 & 0.93 & 0.98 & 41.12 & 5.86 & 0.96 \\
\hline 30.7 & 6000 & 0.99 & 0.93 & 0.99 & 41.12 & 5.86 & 0.96 \\
\hline 30.7 & 7000 & 1.00 & 0.93 & 0.99 & 41.12 & 5.86 & 0.96 \\
\hline 30.7 & 8000 & 1.01 & 0.93 & 1.01 & 41.14 & 5.88 & 0.96 \\
\hline
\end{tabular}

From the Table 5, it is clear that the spin of the baseball has got no significant effect on the injury. In the case of $\mathrm{X}$ and $\mathrm{Z}$ spins the $\mathrm{VC}_{\max }$ values $0.98 \pm 0.03$ and for the $\mathrm{Y}$-spin it is 0.93 which is approximately $3 \%$ less than the value calculated using Eq. (1). For the cases of $\mathrm{Y}$-spin, the $\mathrm{VC}_{\max }$ values calculated based on Eq. (1) are exactly as same as the baseball without spin. From these calculations, it is evident that the Eq. (5) is applicable to all impact cases of the baseball 
considered and also apparent that spin of the baseball about the axis parallel to the impact direction has got no influence on the blunt thoracic trauma.

\section{Conclusions and future recommendations}

Measurements of the blunt thoracic trauma (viscous injury or $\mathrm{VC}_{\max }$ values) caused by the substantial sports ball impacts using the FE model surrogate MTHOTA, due to its correlation with the human response corridors developed by Wayne State University researchers, are reasonably accurate and results are well correlated with the published results in which 3-RCS was used as the thoracic surrogate. In the present study, viscous injuries are evaluated by taking the comprehensive range of ball impact speeds (i.e., $10-45 \mathrm{~m} / \mathrm{s}$ with an increment of $5 \mathrm{~m} / \mathrm{s}$ ) into consideration. MTHOTA being an FE model surrogate offers so many advantages such as a fast solution, ease in setting up the simulation run, no ambiguity in impact location, etc. In case of solid ball sports, like any other sports activity, primary objective is to avoid the injuries, for which a tool to measure the injury is paramount and MTHOTA served the purpose very well.

The following conclusions were drawn from the outcome of the impact experiments carried out in virtual testing environment, in which thorax surrogate MTHOTA was impacted with baseballs (both soft-core and synthetic) and the cricket ball.

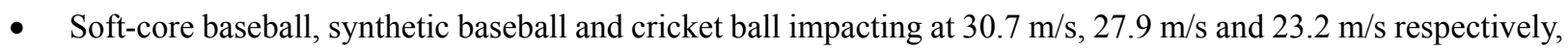
have caused injuries equivalent to $\mathrm{VC}_{\max }=1 \mathrm{~m} / \mathrm{s}$ (i.e., $25 \%$ percent probability for AIS3+ injuries).

- Material of the solid sports ball has got great influence on the severity of the thoracic injuries. At any given speed, both baseballs (Soft-core and synthetic) possess the same amount of kinetic energy as they are equal in weight. Effect of size is also same as they are similar in shape and size. At $30.7 \mathrm{~m} / \mathrm{s}$ impact speed, measured $\mathrm{VC}_{\max }$ is $1 \mathrm{~m} / \mathrm{s}$ and $1.27 \mathrm{~m} / \mathrm{s}$ for soft-core baseball and synthetic baseball respectively. Means, probability for AIS3 + thoracic injuries with the synthetic baseball has become doubled. At the same time, it is important to note that at usual pitching speeds ( $>40 \mathrm{~m} / \mathrm{s}$ ), soft-core baseballs did not offer any safety to the thorax.

- Though the size of a cricket ball is almost same as baseball, weight is approximately 20 grams more. From the results, it is evident that the weight of the ball has got great influence on the blunt thoracic trauma.

- Peak viscous response of the MTHOTA surrogate versus baseball impact speed plot yielded the relation $\mathrm{VC}_{\max }$ $\propto(\mathrm{v})^{2.548}$, which can be used for evaluating blunt thoracic trauma caused by the baseball impacting at any speed.

- Peak viscous response of the MTHOTA surrogate versus peak rate of change in kinetic energy of the MTHOTA plot yielded the relation $\mathrm{VC}_{\max }=0.0314\left(\mathrm{KE}_{\max } / \mathrm{t}\right)^{0.9489}$. This relation can be used for the evaluation of the blunt thoracic trauma caused by spinning or oblique baseball impacts.

- Spin of the baseball about axes perpendicular to the impact direction has got very little influence (only $\pm 4 \%$ ) on the $\mathrm{VC}_{\max }$. From the collapse of the corrugated sheet of MTHOTA upon the impact of spinning ball, it is clear that depending upon the spin direction, it may reduce or increase the load on the cardiac region. Therefore, spin of the ball has got influence on the heart related injuries.

- Stored Energy Criterion and Energy Storing Rate Criterion (Wang, 1989) have yielded the relations Peak stored energy $\propto(\text { Peak deflection } \text { мтнотА })^{1.253}$ and Rate of peak stored energy $\propto($ Peak deflection MTHOTA $\times$ Rate of peak deflection мтнотА $)^{0.5554}$ respectively. These two relations were found to be not in correlation with the analytical expressions derived by Wang (1989) using Lobdell's lumped mass mathematical model of the thorax.

\section{Acknowledgements}

The study presented in the paper is a part of a major project 'Development and validation of a Mechanical THOrax for Trauma Assessment (MTHOTA)'. Principal author thanks 'Livermore Software Technology Corporation, USA' for providing the educational license for four months. Also, thanks 'Mindglow India Private Limited, Bangalore, India' for providing resources and 'Amerigo Structural Engineers Private Limited, Bangalore' for providing necessary funds for the successful completion of the project. 


\section{References}

Bell, P., Spondylolysis in fast bowlers: principles of prevention and a survey of awareness among cricket coaches, British Journal of Sports Medicine, Vol. 26, No.4 (1992), pp. 273-275.

Bir, C., \& Viano, D. C., Design and injury assessment criteria for blunt ballistic impacts, Journal of Trauma, Vol. 57, No. 6 (2004), pp. 1218-1224.

Bir, C. A., The evaluation of blunt ballistic impacts of the thorax, (PhD Dissertation), Wayne State University, Detroit, Michigan, USA, (2000).

Cheng, N., Takla, M. \& Subic, A., Development of an FE model of a cricket ball, Procedia Engineering, Vol. 13, (2011), pp. 238-245.

Crisco, J. J., Hendee, S. P. \& Greenwald, R. M., The influence of baseball modulus and mass on head and chest impacts: a theoretical study, Medicine and science in sports and exercise, Vol. 29, No. 1 (1987), pp. 26-36.

Crisco, J. J., Greenwald, R. M., Blume, J. D. \& Penna, L. H., Batting performance of wood and metal baseball bats', Medicine and science in sports and exercise, Vol. 34, No. 10 (2002), pp. 1675-1684.

Dau, N., Development of a biomechanical surrogate for the evaluation of commotio cordis protection. (PhD Dissertation), Wayne State University, Michigan, USA, (2012).

Davids, K. \& Morgan, M., The effects of helmet design and bowling speed on indices of stress in cricket batting' Ergonomics, Vol. 31, No. 11 (1988), pp. 1665-1671.

Doerer, J. J., Haas, T. S., Estes, N. A. M., Link, M. S. \& Maron, B. J., Evaluation of Chest Barriers for Protection Against Sudden Death Due to Commotio Cordis, The American journal of cardiology, Vol. 99, No. 6 (2007), pp. 857-859.

Drane, P. \& Sherwood, J., Characterization of the effect of temperature on baseball COR performance, Engineering of sport, Vol. 5, No. 2 (2002).

Elliott, B., Burnett, A., Stockill, N. \& Bartlett, R., The fast bowler in cricket: A sports medicine perspective', Sports Exercise and Injury, Vol. 1, No. 4 (1995), pp. 201-206.

Hallquist, J. O., LS-DYNA Keyword User's Manual, Volume II, Livermore Software Technology Corporation, USA, (2007).

Herrmann, L. \& Peterson, F., A numerical procedure for viscoelastic stress analysis, in Seventh Meeting of ICRPG Mechanical Behavior Working Group, Orlando, FL, CPIA Publication: proceedings of the Seventh Meeting of ICRPG Mechanical Behavior Working Group, Orlando, FL, USA, (1968), pp. 60-69.

Janda, D. H., Viano, D. C., Andrzejak, D. V. \& Hensinger, R. N., An Analysis of Preventive Methods for BaseballInduced, Chest Impact Injuries, Clinical Journal of Sport Medicine, Vol. 2, No. 3 (1992), pp. 172-179.

Janda, D. H., Bir, C. A., Viano, D. C. \& Cassatta, S. J., Blunt chest impacts: assessing the relative risk of fatal cardiac injury from various baseballs, Journal of Trauma, Vol. 44, No. 2 (1998), pp. 298-303.

Lobdell, T. E., Kroell, A. K., Schneider, D. C., Hering, W. E. and Nahum, A. M., Impact response of the human thorax. In Human Impact Response, (1973), pp. 201-245.

Madias, C., Maron, B. J., Weinstock, J., Estes, N. A. M. \& Link, M. S., Commotio Cordis—Sudden Cardiac Death with Chest Wall Impact, Journal of Cardiovascular Electrophysiology, Vol. 18, No. 1 (2007), pp. 115-122.

Maron, B. J. \& Estes III, N. A. M., Commotio cordis, New England Journal of Medicine, Vol. 362, No. 10 (2010), pp. 917-927.

Munroe, B. J. \& Sherwood, J. A., Finite Element Modeling of a Baseball, Procedia Engineering, Vol. 34, No. 0 (2012), pp. 610-615.

Mustone, T. J. \& Sherwood, J. A., Using LS-DYNA to characterize the performance of baseball bats, in 5th International LS-DYNA Users Conference, September: proceedings of the 5th International LS-DYNA Users Conference, (1998), pp. 21-22.

Nicholls, R. L., Miller, K. \& Elliott, B. C., Numerical analysis of maximal bat performance in baseball, Journal of Biomechanics, Vol. 39, No. 6 (2006), pp. 1001-1009.

Smith, L., Evaluating baseball bat performance, Sports Engineering, Vol. 4, No. 4 (2001), pp. 205-214.

Tanaka, K., Sato, F., Oodaira, H., Teranishi, Y. \& Ujihashi, S., Construction of the finite-element models of golf balls and simulations of their collisions, Proceedings of the Institution of Mechanical Engineers, Part L: Journal of Materials Design and Applications, Vol. 220, No. 1 (2006), pp. 13-22. 
Thota, N., Epaarachchi, J. \& Lau, K. T., Development and validation of a thorax surrogate FE model for assessment of trauma due to high speed blunt impacts, Journal of Biomechanical Science and Engineering, Vol. 9, No. 1 (2014), pp. JBSE0008-JBSE.

Thota, N., Eepaarachchi, J. \& Lau, K. T., Develop and validate a biomechanical surrogate of the human thorax using corrugated sheets: a feasibility study, in Proceedings of the 7th Australasian Congress on Applied Mechanics (ACAM 7), Adelaide, South Australia, Australia, (2012).

Viano, D. C. \& King, A. I., Biomechanics of chest and abdomen impact, The Biomedical Engineering Handbook, Vol. 1, (2000), pp. 369-380.

Viano, D. C., Lau, I. V., Andrzejak, D. V. \& Asbury, C., Biomechanics of injury in lateral impacts, Accidents Analysis \& Prevention, Vol. 21, No. 6 (1989), pp. 535-551.

Viano, D. C., Bir, C. A., Cheney, A. K. \& Janda, D. H., Prevention of commotio cordis in baseball: an evaluation of chest protectors, Journal of Trauma, Vol. 49, No. 6 (2000), pp. 1023-1028.

Walker, H. L., Carr, D. J., Chalmers, D. J. \& Wilson, C. A., Injury to recreational and professional cricket players: Circumstances, type and potential for intervention, Accident Analysis \& Prevention, Vol. 42, No. 6 (2010), pp. 2094-8.

Wang, J. T., Analytical Studies of Injury Criteria for the Thorax, Journal of Biomechanical Engineering, Vol. 111, No. 2 (1989), pp. 128-135. 